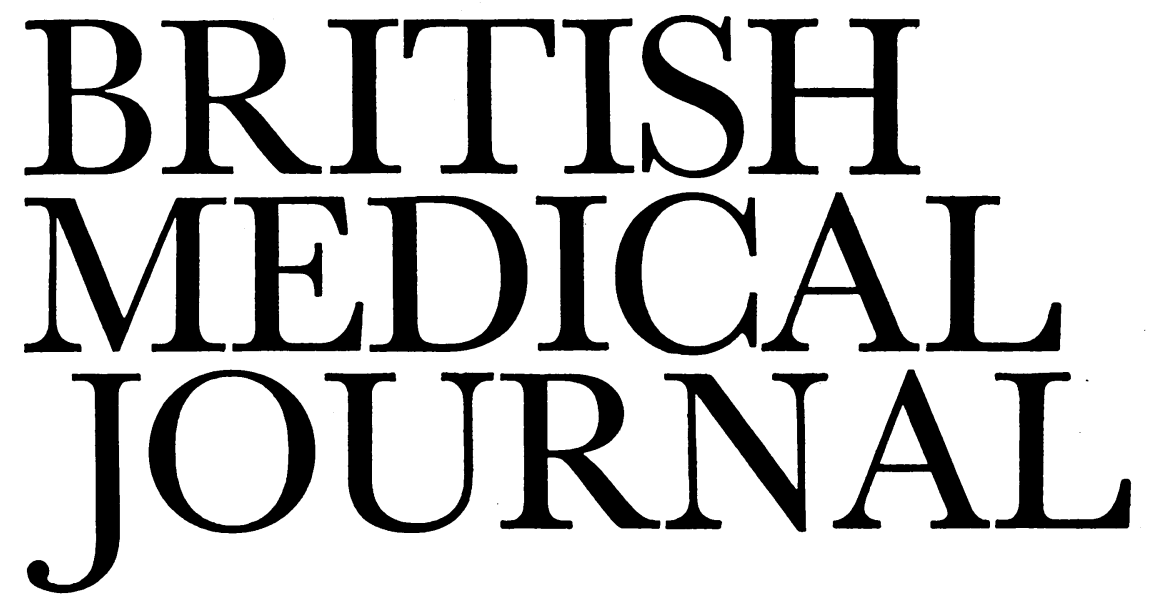

LONDON, SATURDAY 26 JULY 1980

\title{
Perinatal and neonatal mortality: a welcome report
}

More than any other specialty, obstetrics is practised in the spotlight of public opinion. The past decade has seen a continuing debate about home-versus-hospital delivery; wide publicity for doubts about induction and fetal monitoring, the gospel according to Leboyer; and-most important and most sustained-criticism of Britain for having a higher perinatal mortality rate than its close European neighbours. At times (and the $B M \mathcal{F}$ has been among those guilty) critics have claimed to see simple ways to improve the British results, such as following the French example and giving women financial incentives to attend early for antenatal care: but Mrs Renée Short's Parliamentary Social Services Committee, whose report $^{1}$ on perinatal and neonatal mortality was published last week, has avoided the pitfall of instant solutions. Its analysis of the present practice of obstetrics and perinatal paediatrics is careful to distinguish certainties from probabilities and facts from professional opinions (no matter how strongly held); its recommendations are radical but should not be seen as controversial.

The report lists the factors responsible for perinatal and neonatal deaths in two categories: lack of education, poverty, poor housing, possibly poor nutrition, unplanned pregnancy, smoking, and excess alcohol, on the one hand; and lack of antenatal care, low birth weight, asphyxia during and after delivery, congenital malformation, and birth injury, on the other. Britain cannot hope to achieve parity with Swedish health statistics so long as the gap remains so wide between the socioeconomic standards in the two countries. The Parliamentary report recognises this, and accepts the difficulty of improving social conditions in the short term; but it argues convincingly that much of the death and handicap suffered by babies of socially disadvantaged mothers can be overcome by medical intervention.

The committee heard evidence from obstetricians, midwives, paediatricians, and many groups representing special interests, and to some extent acted as judge and arbitrator on those issues where opinions are strongly divided. It decided, for example, in favour of delivery in large hospitals rather than small units, GP units, or home delivery; and it was convinced by the advocates of fetal monitoring for all deliveries. The committee was clearly unhappy about some aspects of general practitioner obstetrics, and has recommended that GPs who want to deliver their patients should have the Diploma of the
Royal College of Obstetricians and Gynaecologists; that (and here the parallel with midwives impressed the MPs) doctors who want to stay on the obstetric list should have to attend regular refresher courses; and that all pregnant women should be seen at least twice by a consultant obstetrician. As a final quality control on both GP and consultant deliveries the report proposes that a maternity services committee should be set up in each health district, consisting of an obstetrician, a paediatrician, a GP on the obstetric list, and a midwife; this committee would co-ordinate the maternity services locally and also carry out a regular audit of all perinatal deaths. These proposals will be resisted by some general practitioner obstetricians, but a review of training in obstetrics is certainly required. Last month (28 June, $p$ 1637) the BMA Council was disturbed enough by a report from the chairman of the GMS Committee of the unsatisfactory training given to some undergraduates to agree to meet the General Medical Council to discuss the matter. As obstetrics becomes more specialised and technological, account needs to be taken of these changes in defining the future role of general practitioner obstetricians.

Having been convinced that modern obstetric techniques can-to some extent-compensate for the hazards to the fetus of adverse social circumstances, the committee has spelt out a programme to put that policy into action. Firstly, medical intervention has to be aimed at the women at high risk; secondly, standards of equipment and of staffing have to be improved so that deprived areas are no longer underprovided; and, thirdly, improvements are needed in the collection and analysis of data on the short-term and long-term results of medical intervention.

Starting at the beginning, the report argues that antenatal clinics are too often overcrowded and off-putting. If women at high risk are to be urged to attend they must not be discouraged by delays or impersonal treatment; so the overall quality of these clinics will have to be improved. The report recommends establishing minimum guidelines for staffing (doctors, nurses, midwives, and clerical officers); reducing the number of visits for low-risk mothers; creating neighbourhood clinics; and making greater use of shared care with GPs. The Trades Union Council, the Health Education Council, and the Confederation of British Industry are to be asked to help tell women about the importance of antenatal care and their entitlement to paid time off to attend clinics. The committee 
did not, however, accept unquestioningly that all the features of orthodox antenatal care are of proved benefit and it has asked the DHSS and the Medical Research Council to fund, as a priority, research to determine how best antenatal care can reduce perinatal and neonatal mortality and morbidity.

One aspect of health during pregnancy on which there is no dispute is the danger to the fetus if the mother smokes. An earlier report ${ }^{2}$ from this same committee had called for urgent Government action to discourage smoking. The current report repeats those strong recommendations "that every means, including the banning of advertisements and increasing levels of taxation" should be used: and it adds that a special warning about smoking in pregnancy should be put on all cigarette packets.

The committee's approach to antenatal care is repeated in later chapters; indeed, throughout the report three themes recur. More staff are needed: and among the specific recommendations are a $50 \%$ expansion of the consultant grade in obstetrics and gynaecology (with more consultants concentrating on obstetrics); an "urgent" increase in the number of consultant paediatricians to at least the 746 recommended by the Court Report ${ }^{3}$; and a national recruiting campaign to encourage nurses to train as midwives-whose pay should be improved above their basic nursing salaries. Better facilities are needed: the number of cots for neonatal intensive care should be increased from 176 to 400 , and every region should have one or two specialist referral units and between three and five subregional centres providing facilities that cannot be available in every district hospital. Minimum requirements for both equipment and staff should be drawn up by the DHSS in consultation with professional bodies. And better monitoring is needed. The report suggests that each region should set up a perinatal working party with the duty of monitoring obstetric and neonatal work, rationalising services, and reviewing perinatal deaths, and recommends studies of the long-term outcome for infants at high risk of mental and physical handicap.

So this is a detailed, authoritative report which comes down unequivocally on the side of specialist skills and the setting of minimum standards. The committee recognises that there is an "unresolvable dilemma that the understandable preferences of mothers in regard to place of delivery may not be compatible with the requirements for the maximum lowering of perinatal and neonatal mortality." Much of the demand for delivery at home or in small units would disappear if the large units lost their reputation for impersonal lack of humanity. The improvements in facilities and in staffing recommended by the report would help achieve that change by relieving staff of unreasonable pressures on their time-and obstetricians are already responding to the climate of public opinion. Mrs Short's distinguished predecessors (Peel, ${ }^{4}$ Sheldon, ${ }^{5}$ and Court $^{3}$ ) were consigned to the shelves of the DHSS with no action taken. Clearly the Government's economic policies will make it reluctant to increase public spending by expanding any section of the NHS. Anticipating this response, the committee has examined the financial implications of its recommendations in greater detail. Experience in Sweden has shown that perinatal morbidity (and so handicap) falls in parallel with perinatal and neonatal mortality. While the committee's detailed calculations may be challenged, the trend is unlikely to be wrong: and the potential saving of $f 150 \mathrm{~m}$ in the next 10 years by preventing handicap should appeal to the Treasury. For once, humanitarian and economic considerations point in the same direction: by implementing the report's recommendations fully and quickly the Government would be investing in the future. And what else is our oil money for?
1 Social Services Committee. Perinatal and neonatal mortality. Second report from the Social Services Committee 1979-80. London: HMSO, 1980.

${ }^{2}$ First report from the Expenditure Committee 1976-7. Recommendations 23-32. London: HMSO, 1977.

${ }^{3}$ Committee on Child Health Services. Fit for the future. London: HMSO, 1976. (Court Report.)

${ }^{4}$ DHSS Welsh Office Standing Maternity and Midwifery Advisory Committee. Report of the Subcommittee on Domiciliary Midwifery and Maternity Bed Needs. London: HMSO, 1970. (Peel Report.)

${ }^{5}$ DHSS. Report of the Expert Group on Special Care for Babies. London: HMSO, 1971. (Sheldon Report.)

\section{Two jubilees in psychotherapy}

The Tavistock Clinic and the Cassel Hospital, the two leading institutions in Britain in psychotherapy, are celebrating their diamond jubilees this month. They were founded independently in 1920 as pioneer organisations to provide systematic psychotherapy with a psychoanalytic orientation. Both came into the NHS at its formation.

The Tavistock Clinic in north-west London is an entirely outpatient clinic. From its inception it has concentrated on providing a multidisciplinary approach to psychotherapy and on teaching emerging skills in this discipline not only to future specialists but also to all those concerned with mental health and human relations.

After the second world war the Tavistock Clinic shifted the emphasis of its work from the simple provision of psychotherapy for two reasons. Firstly, the demand for psychotherapy was such that the clinic could clearly never provide more than a tiny fraction. Secondly, it had become apparent that most people in need of psychological help went to sources which were not part of the psychiatric services and, apart from family doctors, might not even be connected with the medical profession: social workers, health visitors, teachers, hostel wardens, or clergymen. For many years, therefore, one of the clinic's main efforts has been to develop and support the work of these primary caregivers.

The work of the clinic continues to be rooted in concepts derived from psychoanalysis and is carried out in multidisciplinary teams composed of members of five disciplines (psychiatry, clinical psychology, educational psychology, child psychotherapy, and social work) working in three departments (adult, adolescent, and children and parents).

The clinic provides a service for outpatients in individual and group therapy, and it also provides marital and family therapy. Training, however, has continued to expand and is now a big part of the clinic's work. Each year about 1000 students from all parts of Britain attend the training activities and some 50 others come from overseas. The training offered is of two kinds. Firstly, there is training for members of the five disciplines to provide specialists who will be able both to practise and to teach elsewhere the dynamic skills practised within the clinic. Secondly, the clinic runs part-time courses, many of which are for the primary caregivers to whom people turn in times of distress. In addition, the clinic provides a resource of skills that can be taken out into the community; and staff work in institutions such as schools, residential homes, and health centres to help the staff in dealing with the psychological problems they encounter in their work. 